Military Technical College

Kobry El-Kobbah,

Cairo, Egypt

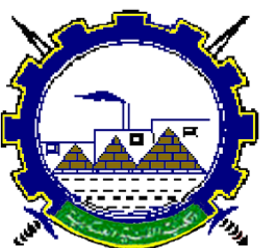

I.C.E.E.2016 $8^{\text {th }}$ International Conference

on

Chemical \& Environmental

Engineering

$19-21$ April 2016

\title{
IEA-1
}

\section{Simulation of Industrial Production of Value Added Chemicals from Primary Resources through Pilot Plant Operations}

\author{
By \\ A.K.Ismail
}

\begin{abstract}
Mineral resource are the backbone of industrial development. Egypt is blessed by having mostly all mineral resources in huge reserves .Generally, these minerals are exported in its crude form whereas the importing countries process it and export the products to the country of origin causing economic unbalance. Recently, the Egyptian government limits the exportation of mineral resources in its crude form. The Central Metallurgical Researchers and Development Institute (CMRDI) , Cairo , Egypt develops technologies for the production of value added products from Egyptian ores, thus maximizing its value and creating new job opportunities and encouraging investment . The technologies developed are based mainly on pilot plant testing which simulates the industrial operations. The pilot facilities include unit operations and processes of crushing, grinding, classification, flotation, magnetic separation, heavy media separation , thermally controlled reactors , solid - liquid separation by different filter types, crystallization and drying. Among the technologies developed are processing of phosphate ores for phosphoric acid and compound fertilizers, betonies for drilling fluids and binding agent for foundry sand moulds and bleaching earth for edible oils, kaolin upgrading for ceramic and paper application, white sand washing for glass and silicon manufacturing, processing of manganese ores for ferroalloys, processing of ilmenite for titanium based chemicals and many other technologies. The paper reviews some of these technologies and present a model of transferring laboratory results to industry thus narrowing the gap between theory and practice.
\end{abstract}

Keywords:

Beneficiation,roasting,smelting, reduction,leaching,filtration,crystallization.

* Former vice President:

Central Metallurgical Researchers and Development Institute, Cairo, Egypt

P.O.B 87 Helwan, Cairo, Egypt

Mobile: ( 02 ) 01005073650 Tel: ( 202 ) 27142452 Fax: ( 202 ) 27142451

info@.cmrdi.sci.eg,www.cmrdi.sci.eg 